\title{
Repensar a regularização fundiária como política de integração socioespacial
}

\author{
RAFAEL SOARES GONÇALVES
}

A S POLÍTICAS de regularização fundiária das favelas consolidaram-se no Brasil, como política urbana, a partir do início da década de 1980. Apesar da construção gradual de uma profunda reflexão sociojurídica sobre a regularização fundiária no país, o balanço registrado dos programas de legalização do solo é, todavia, ao menos por enquanto, extremamente negativo. Tais iniciativas se perdem nos meandros intermináveis da burocracia brasileira, revelando a incapacidade da estrutura jurídica atual do país de integrar à formalidade uma grande parcela da população urbana. $\mathrm{O}$ sistema jurídico do país, como sustenta James Holston (1993, p.77), incorporou, de maneira ágil, a intenção de perpetuar a falta de soluções jurídicas, por meio de uma enorme variedade de complicações legais, o que nos leva a afirmar, com Clifford Geertz (1999, p.268), que "o espírito jurídico em qualquer tipo de sociedade parece se alimentar tanto da confusão quanto da ordem". Nesse sentido, essa espécie de suspensão da aplicação efetiva do texto da lei, em certas áreas das cidades, exerceu um papel fundamental na configuração das cidades brasileiras.

Sem pretender esgotar as diferentes facetas que a regularização fundiária apresenta, este artigo procura, sobretudo, tecer um panorama do contexto atual da regularização fundiária no Brasil. Ele analisa, assim, tanto os desafios que suscitam as políticas de legalização do solo nas favelas quanto os principais instrumentos jurídicos estabelecidos pela legislação brasileira, após a Constituição Federal de 1988. Trata-se de levantar os elementos mais relevantes do debate jurídico atual sobre a regularização fundiária, procurando compreender de que maneira a legalização do solo pode tornar-se uma política pública de integração socioespacial das camadas mais desfavorecidas da população urbana.

\section{A consolidação da regularização fundiária como política urbana no Brasil}

A promulgação da Constituição Federal em 1988 coroou o longo processo de democratização do país iniciado, ainda, no final dos anos 1970. A democratização do país foi a ocasião propícia para uma reflexão mais acurada sobre a integração socioespacial das camadas urbanas mais desprotegidas, tanto no plano jurídico quanto no plano social. Diante das pressões dos movimentos sociais urbanos, o capítulo constitucional sobre a política urbana (artigos 182 e 
183) reconheceu que tanto a propriedade quanto a própria cidade devem exercer uma função social. Esse mesmo artigo estabeleceu que o município exerce, de agora em diante, um papel central na elaboração e na aplicação das políticas de desenvolvimento urbano local. $\mathrm{O}$ instrumento de base dessa política é doravante o Plano Diretor municipal, exigência constitucional para todas as cidades com mais de 20 mil habitantes. As disposições desse capítulo constitucional se focalizam, assim, na instituição de medidas aptas a dissuadir a concentração especulativa do solo, assim como possibilitar a legalização das formas informais de acesso à moradia.

Este último aspecto revela-se crucial diante do índice de informalidade fundiária das cidades brasileiras. Segundo Edésio Fernandes (2002, p.52), essa informalidade pode atingir, por exemplo, quase $50 \%$ da população das duas principais metrópoles brasileiras (São Paulo e Rio de Janeiro). Ao regulamentar as disposições do supracitado capítulo constitucional, a lei do Estatuto da Cidade (Lei n.10.257 de 10 de julho de 2001) contribuiu para consolidar a regularização fundiária como uma das principais diretrizes da política urbana no Brasil. Antes de analisarmos as disposições da legislação brasileira sobre esse assunto, impõe-se, inicialmente, uma breve análise das diferentes questões sociopolíticas relativas à legalização do solo.

A regularização fundiária consiste em regularizar a posse dos habitantes e promover a urbanização do local sem recorrer à remoção da população para outras localidades. A regularização fundiária é frequentemente limitada à transferência de títulos fundiários, sobretudo os de propriedade privada. Medida, aliás, preconizada como "solução milagrosa" pelas instituições internacionais e celebrizada, nos últimos anos, pelos trabalhos do economista peruano Hernando de Soto. Os governos dos países em desenvolvimento abandonaram, a partir dos anos 1980, os esforços para a construção em massa de moradias populares na periferia das cidades e se concentraram, sobretudo, na ideia de que a legalização do informal, aliada a uma desregulamentação mais acentuada do mercado imobiliário, poderia atenuar o preço do solo, suscitando, enfim, uma oferta mais consistente de moradias, erguidas, geralmente, pela autoconstrução. $\mathrm{O}$ balanço que se obtém 20 anos mais tarde é, todavia, um enorme fracasso. A regularização fundiária, onde foi efetivamente realizada, liberou o solo e desencadeou uma pressão do mercado imobiliário sobre os bairros beneficiados que eram, até então, relativamente protegidos, justamente em razão da sua ilegalidade. $\mathrm{O}$ fenômeno atual de segregação urbana torna-se, assim, mais um produto derivado das leis de mercado que o resultado da recusa, por parte das autoridades públicas, do reconhecimento oficial da existência dos bairros informais. A solução do mercado originou outras formas de exclusão que apenas fizeram aumentar o círculo de informalidade, agora concentrado nas regiões cada vez mais periféricas, insalubres e/ou ecologicamente precárias das cidades.

Esse modelo, ao menos no caso específico das favelas, foi apenas parcialmente aplicado no Brasil. A política de urbanização das favelas, implementada a 
partir dos anos 1980, não foi necessariamente seguida da regularização fundiária plena desses espaços. A ilegalidade fundiária, conjugada à violência imposta pelos narcotraficantes num grande número de favelas, desestimula, nos dias atuais, a entrada dos grandes promotores imobiliários no mercado imobiliário das favelas. O fim das políticas de remoções em massa e a ausência de um controle público mais efetivo sobre o crescimento das favelas asseguraram, todavia, a relativa segurança da posse dos habitantes das favelas e o florescimento do mercado imobiliário no interior desses espaços. Esse mercado se apresenta concentrado nas mãos de alguns "latifundiários", muitas vezes ligados às redes mafiosas locais. A flexibilidade urbanística nas favelas permite, ainda, uma oferta consistente de habitações a preços reduzidos. A despeito da especulação imobiliária, as favelas se revelam, pelo menos por enquanto, um relevante meio de acesso à moradia para as camadas mais desfavorecidas das metrópoles brasileiras.

Nesse contexto, a regularização fundiária deve-se concentrar menos sobre uma lógica mercadológica de fluidificação das transações imobiliárias e de alargamento da base fundiária fiscal do município do que sobre a redução da insegurança que afeta as relações fundiárias, como aliás já destacou a campanha pela segurança da posse, promovida pela UN-Habitat, desde $1997 .{ }^{1}$ A precariedade jurídica do acesso ao solo nas favelas sempre serviu como justificativa não somente para as expulsões arbitrárias, mas também para a ausência de serviços públicos adequados nesses espaços. A insegurança fundiária também limitou o investimento dos moradores em suas casas e em seus bairros. A regularização fundiária se manifesta, assim, como um elemento imprescindível para se materializar o direito à moradia, integrando, aliás, esse direito específico ao leque de direitos que constitui o direito à cidade.

A legalização da moradia garante, de fato, direitos sociopolíticos às populações das favelas que adquirem recursos jurídicos indispensáveis para enfrentar os diferentes conflitos de ordem fundiária/imobiliária, seja entre vizinhos, seja ante os pretensos proprietários dos terrenos ocupados pela favela, ou mesmo ante as autoridades públicas. A regularização fundiária pode, por sua vez, desempenhar um importante papel na planificação urbana, por meio da imposição de regras urbanísticas às construções e ao uso do solo nas favelas. Dependendo da natureza do título outorgado aos habitantes, ela pode até mesmo contribuir ativamente para a gestão do fundiário, limitando tanto a excessiva valorização do solo quanto o aumento da exclusão espacial no interior das metrópoles.

O processo de regularização fundiária suscita iniciativas públicas de diferentes naturezas: em primeiro lugar, ela exige intervenções de ordem urbanística, a fim de suprimir possíveis situações que apresentem riscos às populações faveladas e permitir ulteriormente a instalação e/ou a melhoria dos serviços públicos nesses espaços. Ela possui, também, um importante aspecto administrativo de gestão do espaço, por meio das medidas voltadas para o endereçamento do bairro, o reconhecimento administrativo das ruas, a identificação dos habitantes e das construções no cadastro fiscal do município, a elaboração e o 
registro do Plano de Alinhamento (PAL) na prefeitura e no registro de imóveis, assim como, finalmente, a promulgação de normas urbanísticas referentes ao uso do solo. A regularização fundiária envolve, finalmente, uma reflexão de ordem propriamente jurídica, concernindo a legitimação da posse dos habitantes pela transferência de títulos, individuais ou coletivos, de direitos reais aos moradores. ${ }^{2}$

\section{Aspectos jurídicos da regularização fundiária no Brasil}

A chave da insegurança fundiária, segundo Joseph Comby $(2007$, p.38), não está tanto na carência de meios técnicos (cadastro informatizado, estudos topográficos, qualidade de demarcações etc.), mas geralmente na inadequação do sistema jurídico e da máquina administrativa para atender às realidades sociais específicas de cada localidade. A legislação brasileira, no que diz respeito à regularização fundiária, tem feito, certamente, consideráveis progressos nessas últimas décadas, mas os procedimentos de legalização do solo permanecem bastante complexos, dificultando os êxitos dessas iniciativas. A complexidade da gestão fundiária no Brasil se explica, em grande parte, pelos inúmeros procedimentos formais constituídos justamente para evitar possíveis fraudes e pelo zelo desproporcional pela proteção dos direitos de propriedade, o que dificulta toda e qualquer releitura mais social do exercício desses direitos. Essa formalidade excessiva do direito brasileiro, aliada ao sistema privado, complexo e frequentemente corrompido (Holston, 1993, p.71) de gestão do cadastro de imóveis pelos cartórios no Brasil, contribuiu para endossar a apropriação bastante desigual do solo, quase sempre beneficiando a concentração fundiária da propriedade nas mãos de alguns poucos beneficiados.

Antes de analisarmos a natureza jurídica dos títulos fundiários, parece-nos importante descrever, sucintamente, os principais procedimentos necessários à regularização fundiária das favelas no Brasil. A autoridade responsável pelo projeto de regularização, normalmente a prefeitura, deve, primeiramente, delimitar o lugar a ser regularizado, por meio de estudos topográficos e de fotos aéreas, assim como fazer um recenseamento das construções e dos habitantes da favela. É necessário, igualmente, identificar os proprietários das glebas onde se encontra a favela que será regularizada, realizando um detalhado estudo fundiário. A natureza da propriedade do solo (bens públicos ou privados), assim como a natureza e o prazo da posse dos ocupantes são fatores extremamente importantes para a escolha do título fundiário que poderá ser ulteriormente pleiteado pelos ocupantes.

A área, alvo da regularização fundiária, deve, frequentemente, ser declarada Zona Especial de Interesse Social (Zeis) por uma lei municipal. Essa ferramenta jurídica prevê a possibilidade de flexibilizar localmente as diferentes regras urbanísticas, quando interesses sociais se impõem. O emprego das Zeis põe fim à ideia, frequentemente retomada pelas autoridades públicas, de que elas não poderiam instalar serviços públicos nas favelas, em razão da ilegalidade 
urbanística e fundiária desses espaços. O fato de declarar uma zona Zeis permite um controle mais restrito dos poderes públicos sobre as utilizações sociais desses espaços que são, doravante, destinados prioritariamente à habitação de interesse social.

A prefeitura deve, igualmente, elaborar e aprovar o PAL, assim como averbá-lo junto ao registro de imóvel competente. Ela deve, ainda, fixar, por meio de um decreto municipal, os parâmetros específicos de construção e de utilização do solo nas favelas em questão, o que lhe permite, posteriormente, tanto emitir o habite-se aos residentes quanto inscrever essas moradias no cadastro fiscal da Secretaria Municipal da Fazenda. O processo de regularização fundiária termina, enfim, pelo registro definitivo dos títulos fundiários junto ao registro de imóveis. Esse longo percurso encontra, aqui, muitas vezes, mais uma barreira quase instransponível. Além das inúmeras exigências formais impostas pelos cartórios, a regularização da propriedade no Brasil exige, em certos casos, uma decisão expressa do Poder Judiciário que pode retardar, ainda por alguns anos, o procedimento de regularização fundiária. É o caso, por exemplo, da sentença declaratória da usucapião que deve ser registrada no cartório de registro de imóveis, reconhecendo definitivamente o direito à propriedade de seu beneficiário.

A escolha da natureza do título que será entregue às populações faveladas depende, sobretudo, da posse original do solo. As duas ferramentas mais empregadas atualmente são a usucapião especial urbana (UEU), nos casos de terrenos privados, e a concessão de direito real de uso para fins de moradia (Cuem), quando se trata de terrenos públicos.

Segundo o artigo 183 da Constituição Federal, todo ocupante de terrenos - que não é proprietário de um outro imóvel urbano ou rural - pode adquirir a propriedade do solo pela UEU, se ele aí habita há mais de cinco anos, se o proprietário não interveio para recuperar o terreno durante este período, e à condição de que a superfície do imóvel não ultrapasse 250 metros quadrados. A lei do Estatuto da Cidade admitiu a UEU igualmente, sob a forma coletiva, o que é fundamental, tendo em conta o aspecto dinâmico e coletivo da ocupação do solo nas favelas. Surge, então, um condomínio indivisível que não é passível de extinção, salvo em caso de deliberação favorável tomada por, pelo menos, dois terços dos coproprietários e sob a condição de que a área seja completamente urbanizada. Essa abordagem, como constata Rose Compans (2003, p.51), procurou tornar mais simples os procedimentos administrativos e judiciais, mas ela suscitou outras questões e dificuldades, particularmente no que concerne à complexa gestão desses condomínios no interior das favelas. A análise do alcance desse instrumento jurídico é extremamente complexa. A UEU legitimou uma série de ocupações de terrenos urbanos, muitas vezes conservados de modo especulativo, contribuindo para fazer valer o princípio da função social da propriedade. O perigo que se impõe, como bem mencionou Comby (2007), é de que o lapso temporal para reivindicar a UEU seja muito curto, estimulando - em um contexto de ausência de políticas habitacionais - novas ocupações. 


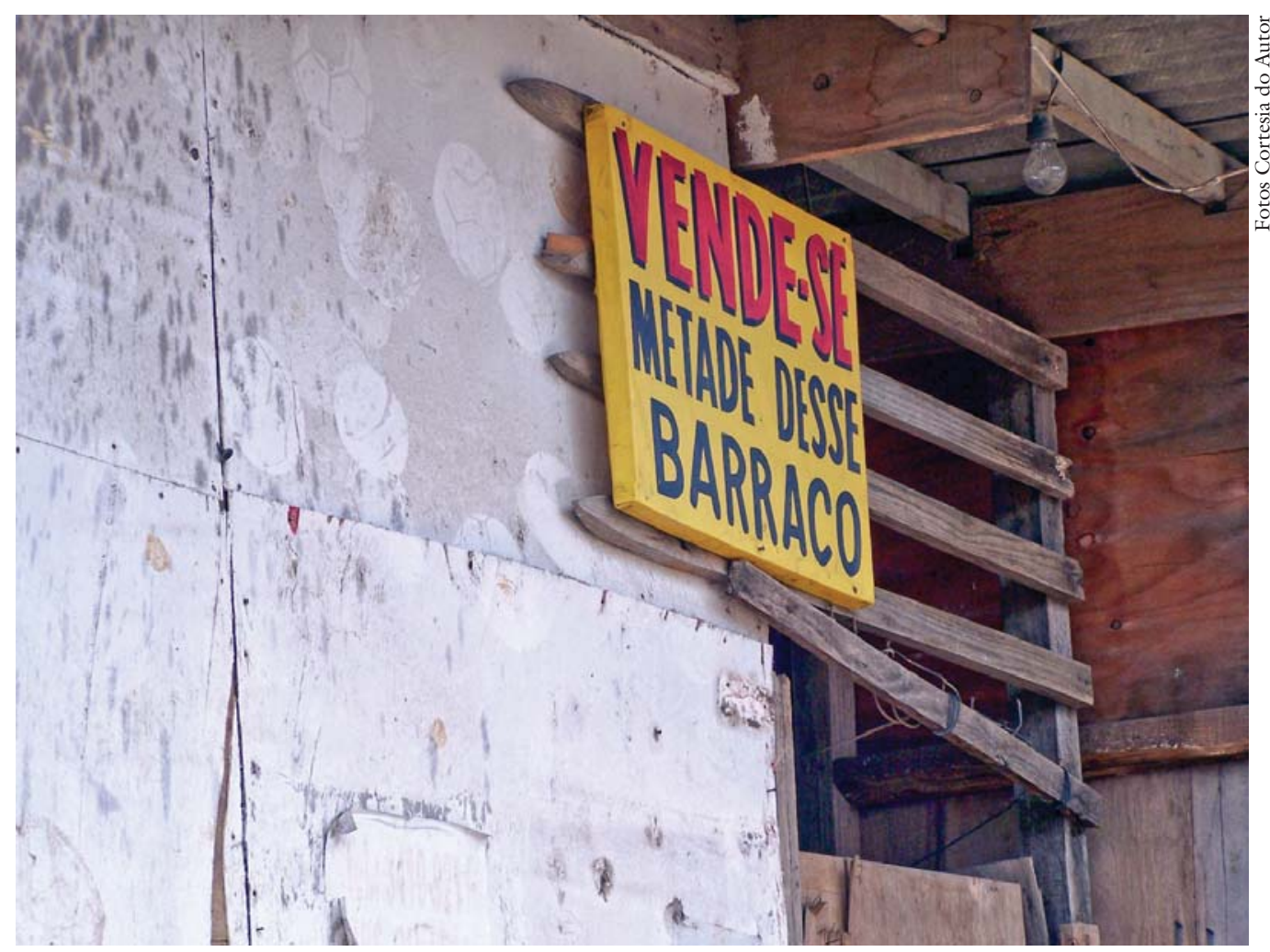

Especulação imobiliária é um mercado consistente nas comunidades carentes do Rio de Janeiro.

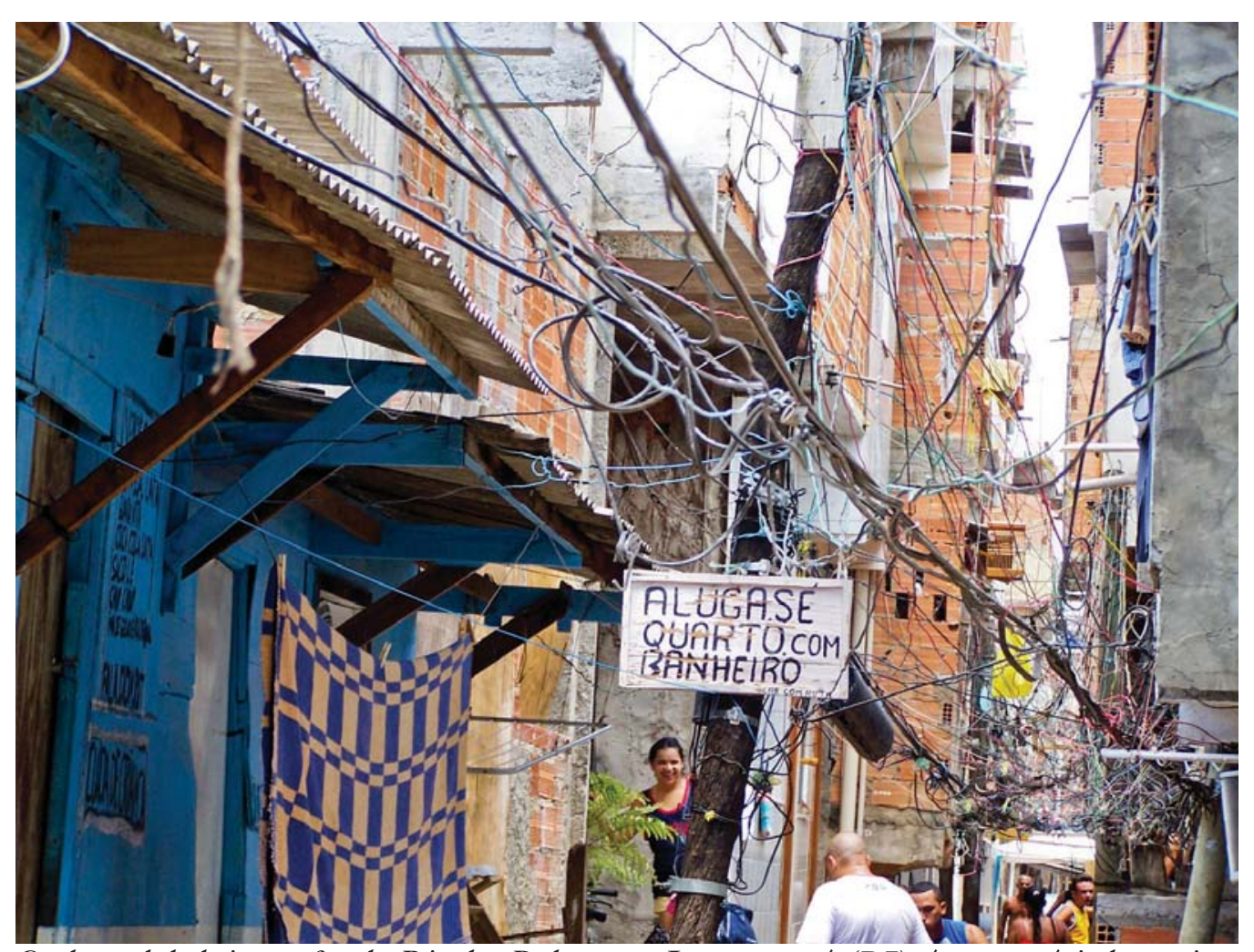

$O$ aluguel de lajes na favela Rio das Pedras, em Jacarepaguá (RJ), é um negócio lucrativo. 
Quanto aos terrenos públicos, certos juristas tentaram em vão aplicar, durante os anos 1990, a partir de uma interpretação hermenêutica do conteúdo do artigo 183 da Constituição Federal, ${ }^{3}$ a concessão de uso ${ }^{4}$ dos terrenos públicos sob as mesmas condições da UEU quanto aos terrenos privados. Esse instrumento jurídico só foi instituído, no entanto, após a adoção da Medida Provisória n.2.220, de 4 de setembro de 2001. Seguindo praticamente as mesmas normas prescritas à UEU, o ocupante de terrenos públicos - ocupados até 30 de junho de 2001 - pode pleitear diretamente à entidade pública proprietária do terreno a atribuição da Cuem de forma individual ou coletiva. ${ }^{5}$ Trata-se, assim, de um direito subjetivo voltado especificamente para moradia do concessionário, o que a diferencia da concessão de direito real de uso estabelecida pela Lei n.271, de 28 de fevereiro de 1967, que se revela, antes de mais nada, uma prerrogativa de natureza facultativa dos poderes públicos. Assim como a UEU, a Cuem só pode ser reconhecida uma única vez ao mesmo ocupante; esse não pode, ainda, ser nem proprietário, nem concessionário de outro imóvel urbano ou rural. Se o terreno apresenta riscos para a vida ou para a saúde dos ocupantes, os poderes públicos devem assegurar esse tipo de concessão numa outra região. No caso dos estabelecimentos comerciais, as autoridades públicas podem atribuir uma autorização de uso, cujo estatuto jurídico é mais precário e desprovido de características de um direito real. A despeito da dificuldade de se aplicarem plenamente certos princípios da atual legislação urbanística, essa consolidou, definitivamente, a urbanização e a regularização fundiária das favelas como política urbana no Brasil.

\section{Refletir a legalização do solo como instrumento de integração socioespacial}

A regularização fundiária revela-se uma operação complexa que atinge diferentes atores urbanos. Diante da descentralização administrativa, proposta pela Constituição de 1988 e, ao menos, até a criação do Ministério das Cidades pelo governo Lula em 2003, a esfera municipal exerceu um papel central e muitas vezes solitário em prol da regularização fundiária. A própria ausência de interesse de tantos favelados pela legalização do solo contribuiu evidentemente para o fracasso desses projetos. Ora, o fim das políticas de remoções assegurou uma certa segurança da posse, o que fez diminuir, em muitas favelas, as reivindicações sociais pela regularização do solo. Essa segurança pode, no entanto, revelar-se enganosa, como observamos na retomada atual do discurso, anacrônico, a favor da remoção das favelas. O impacto do aumento da violência sobre as atividades imobiliárias nos arredores das favelas, aliado à profusão de argumentos ecológicos sobre as ameaças causadas por elas à natureza, tem servido para justificar as críticas atuais às políticas de urbanização de favelas. Nesse contexto, a regularização fundiária deve ser compreendida não somente como um meio de suprimir o status fundiário ilegal dos espaços favelados, mas sobretudo como um meio de garantir a inclusão socioespacial das populações faveladas no tecido urbano. 


\section{As favelas: uma realidade complexa e em transformação}

$\mathrm{O}$ aspecto informal do acesso à moradia nas favelas sofreu profundas mutações nos últimos anos. Apesar de a precariedade jurídica ainda impedir a entrada do grande capital imobiliário nas favelas, as práticas imobiliárias no interior desses espaços assemelham-se cada vez mais àquelas existentes nos bairros ditos formais. Dessa forma, o sucesso dos projetos de legalização do solo depende, necessariamente, da capacidade da legislação urbanística e das políticas de regularização fundiária de levar em conta as particularidades próprias desse mercado imobiliário informal em franca expansão. A questão suscitada pelos imóveis alugados nas favelas parece ser, por exemplo, uma realidade importante que deve ser levada em conta. Quem possui a legitimidade para obter os títulos fundiários? O pretenso proprietário ou o ocupante de fato do imóvel, ou seja, o locatário? A resposta é tão ou mais complexa quando se observa, nas favelas, a prática corrente dos moradores de construir um cômodo suplementar, a fim de alugá-lo para completar o orçamento familiar. Todavia, a realidade desses pequenos proprietários é substancialmente diferente dos grandes latifundiários das favelas que exploraram comercialmente, por vezes, dezenas ou mesmo centenas de imóveis nas favelas. ${ }^{6}$ A questão essencial que se impõe, então, é se as intervenções públicas em favor da legalização do solo nas favelas devem endossar essa realidade fundiária de fato ou conduzir uma ação mais distributiva, concedendo ao ocupante o direito real sobre o imóvel.

As últimas mudanças jurídicas expostas não formulam respostas satisfatórias a essa questão. O locatário não pode, evidentemente, pleitear a UEU, pois, nesse cenário, a ocupação do imóvel não apresenta o animus domini. Por sua vez, tanto a EUE como a Cuem não permitem a acumulação de imóveis, impedindo a concessão de vários títulos a uma mesma pessoa, o que impede a utilização desses instrumentos para aqueles que possuem mais de um imóvel. Assim, restam apenas as outras formas de usucapião, cujo lapso temporal exigido é mais longo, ou então a concessão especial de direito real de uso que não é, sublinha-se uma vez mais, um direito do ocupante do terreno, mas sim uma prerrogativa das autoridades públicas. Ademais, atacar as estruturas do mercado informal de aluguel, sem prever em troca a oferta de habitações populares, limitará drasticamente um importante meio de acesso à habitação no Brasil. Apesar de todas as críticas à exploração comercial de imóveis de aluguéis nas favelas, é preciso admitir que a prática desses promotores informais está suprindo, talvez perversamente, é verdade, o déficit de moradias de nossas metrópoles.

Além da falta de interesse da população favelada pela regularização fundiária, a dificuldade em regularizar o solo nas favelas se manifesta também pelo fato de que os diferentes círculos de poder nas favelas apoiam-se, fortemente, sobre o aspecto informal do solo para atribuir seu controle interno. As associações de moradores, por exemplo, obtêm importantes recursos ao receberem uma porcentagem sobre as transações imobiliárias locais, para certificar o ato 
de venda do imóvel. ${ }^{7}$ As milícias privadas, por sua vez, recebem igualmente uma porcentagem sobre as transferências imobiliárias, investem diretamente no setor imobiliário no interior das favelas, assim como impõem taxas para o funcionamento do comércio local e dos moradores, a título de segurança do local. Toda intervenção sob o aspecto fundiário nas favelas deve, assim, enfrentar a influência local desses diferentes grupos de poder que não estão, evidentemente, dispostos a apoiar uma política que questione tanto a lucrativa gestão local do solo quanto o status de proprietários dos "latifundiários" locais.

Considerando-se que, atualmente, diminuíram-se os questionamentos, quanto ao regime informal que rege os direitos de posse no interior das favelas, o fato de estar na informalidade - aparentemente excluído dos diferentes recursos que a legalidade oferece - permite reduzir os custos inerentes à formalidade imobiliária (taxas, impostos...), contribuindo, assim, paradoxalmente, para a integração socioespacial dos favelados. A tolerância às favelas - consideradas, nesse sentido, como espaços extralegais no seio das cidades - consolida, enfim, um tipo perverso de integração que dificulta, aos favelados, um exercício pleno da cidadania, pautado pela conquista de direitos. Ademais, certos custos sociais desse tipo de inclusão (equipamentos públicos deficientes, falta de segurança pública, condições precárias de certos lares, ambientes ecologicamente frágeis...) são extremamente mais altos do que nos demais bairros da cidade. ${ }^{8}$

A regularização fundiária pode, assim, consolidar um outro tipo de integração desses espaços ao resto da cidade, mas, como ressalta Etienne le Roy (1999, p.249), o título em si não protege (nada nem ninguém) de possíveis arbitrariedades. É, de fato, “o agente quem garante que o Direito descrito no título é definitivo e incontestável. O Estado é, portanto, o único em questão, é ele que produz ou não esta crença na virtude da segurança adquirida através do título de propriedade. Se o Estado tem comportamentos inseguros, a segurança fundiária não pode estar garantida". Enfim, a regularização fundiária não é solução de todos os problemas das favelas, mas deve estimular uma nova presença dos poderes públicos nesses espaços, a fim de consolidar a ideia de que favela é cidade. Por sua vez, a regularização fundiária, como já vimos, pode legalizar o solo, mas reforçar a exclusão da população beneficiada, quando não se preveem mecanismos para desestimular uma excessiva valorização imobiliária. Aproveitando-se da mais-valia fundiária, obtida a partir da concessão de títulos de propriedade, certos moradores vendem muitas vezes suas moradias e se deslocam para outras favelas, em geral ainda mais precárias e distantes. Como já ressaltamos antes, novos instrumentos urbanísticos e jurídicos, como a Zeis, a UEU e/ou a Cuem podem atenuar esse processo.

O Projeto de Lei federal n.3.057, de 2000, sobre a responsabilidade territorial, enfoca particularmente esse problema, sublinhando o caráter sustentável que deve almejar toda política de regularização fundiária. Segundo o artigo $2^{\circ}$, II do citado projeto de lei, a regularização fundiária sustentável é o conjunto 
de medidas jurídicas, urbanísticas, ambientais e sociais, promovidas pelo poder público por razões de interesse social, que procura adaptar as aglomerações informais às conformações legais, de modo a assegurar o direito social à moradia, ao pleno desenvolvimento das funções sociais da propriedade urbana e ao direito ao meio ambiente ecologicamente equilibrado. $\mathrm{O}$ artigo 81 destacou, igualmente, que a regularização fundiária sustentável deve priorizar a permanência, na área ocupada, das populações desfavorecidas, assegurando-lhes tanto os níveis adequados de habitação quanto a melhoria das condições de sustentabilidade urbanística, social e ambiental. Esse projeto de lei prioriza, assim, a integração socioespacial dos habitantes, estimulando a articulação da regularização fundiária com outras políticas urbanas mais amplas, como as que concernem à oferta de casas populares, ao saneamento básico, à mobilidade urbana e à criação de empregos. Certos aspectos desse projeto de lei foram, aliás, confusamente evocados no capítulo sobre a Regularização Fundiária da MP n.459, de 25 de março de $2009,{ }^{9}$ que dispõe sobre o Programa Minha Casa, Minha Vida e a regularização fundiária de assentamentos urbanos.

\section{À guisa de conclusão: obter títulos ou assegurar direitos?}

O direito urbano atual no Brasil, segundo Ricardo Lira (2007, p.2), reforçou a função social tanto da propriedade quanto da cidade. Atualmente, a propriedade não é mais uma realidade única, uniforme e imutável. A natureza absoluta dos direitos de propriedade é, assim, limitada pelos interesses sociais. $\mathrm{O}$ direito urbanístico deve, então, contribuir para que a configuração da cidade seja menos o produto de interesses privados, e mais o resultado das reivindicações coletivas da sociedade.

Diante das dificuldades de se limitarem os direitos de propriedade, muitos juristas procuraram reforçar a autonomia da categoria jurídica da posse, ante a da propriedade. Como constata o trabalho de Ana Rita Albuquerque (2000, p.35), a função social da propriedade corresponde às limitações fixadas em vista do interesse público e tem por finalidade - a partir de uma reação anti-individualista - instituir um conceito dinâmico da propriedade, a partir das exigências sociais, enquanto a função social da posse faz referência a uma realidade que se manifesta absolutamente indispensável, traduzindo, assim, juridicamente, a expressão da necessidade do indivíduo. Segundo Ana Rita Albuquerque, a posse não é necessariamente subsidiária à propriedade, nem é forçosamente destinada a protegê-la, podendo mesmo opor-se a ela como uma espécie de direito real, dotado de uma função social específica de proteção aos interesses vitais dos indivíduos. Nesse sentido, a categoria jurídica da posse integra, assim, o fato social à norma, suscitando não somente relevantes consequências jurídicas (possessio ad interdicta e possessio ad usucapionem), mas também transformando o fato em si da posse num verdadeiro direito (ibidem, p.16-8). A atual escolha de legitimar a posse, sem necessariamente passar pela inscrição dos títulos de propriedade, demonstra a conscientização atual sobre a importância da situação factual da 
posse em relação aos direitos inscritos no conceito da propriedade privada. Vejamos, por exemplo, o emprego do título de inscrição da ocupação na Secretaria do Patrimônio Federal, previsto pelo artigo $7^{\circ}$ da Lei n.11.481, de 31 de maio de 2007. Trata-se, certamente, de um ato administrativo precário que pode ser suprimido a qualquer momento e que pressupõe o uso efetivo dos terrenos federais pelo ocupante, mas que reconhece a realidade de fato da ocupação dos habitantes.

Por sua vez, os trâmites complexos de registro dos imóveis nos cartórios de registro de imóveis bloqueiam sistematicamente os projetos de regularização fundiária no Brasil e em outros países. Joseph Comby (2007) destaca, por exemplo, que o fracasso da implementação do cadastro é notório em cidades africanas, sendo em parte explicado pela imposição de um sistema de gestão de terras que levou séculos para se consolidar nos países ocidentais. Ainda que a estrutura dos cartórios de registro de imóveis no Brasil mereça, evidentemente, amplas reformas, a fim de torná-las mais simples, eficazes e transparentes, a solução para aperfeiçoar os projetos de regularização fundiária não se encontra, necessariamente, na retirada completa de toda tentativa de registrar o solo das favelas. É preciso, todavia, que os cartórios sejam mais permeáveis às especificidades próprias da urbanização brasileira, onde a informalidade tornou-se um elemento estruturante da urbanização brasileira. Em vez de perpetuar os inúmeros bloqueios que impedem o registro dos imóveis, é preciso, antes de mais nada, procurar realizar um registro que possa garantir, desde o início do processo, uma segurança fundiária satisfatória, indo ao encontro das expectativas que os projetos de regularização fundiária suscitam nas populações diretamente beneficiadas por esses projetos.

Determinadas mudanças legislativas atuais tentam responder a essa questão, como mostram as disposições do artigo $6^{\mathrm{O}} \$ 1^{\mathrm{O}}$ da Lei Federal n.9.636, de 18 de maio de 1998 (redação estabelecida pela Lei n.11.481, de 31 de maio de 2007) sobre o instrumento da demarcação urbanística. Segundo esse artigo, é possível registrar, precariamente, o conjunto de terrenos ocupados (por exemplo, a demarcação urbanística da favela) pelas populações desfavorecidas, onde não é possível distinguir as diferentes parcelas para uma regularização posterior plena, por meio da concessão de títulos fundiários definitivos. A MP n.459 previu, igualmente, a demarcação urbanística, assim como foi instituído o título de legitimação da posse que assegura aos ocupantes de terrenos privados, isentos de litígios, a obtenção de um título fundiário de legitimação da posse que pode ser, ao término de cinco anos, convertido em um título de propriedade privada, sem ser necessário nenhum trâmite longo e penoso no Poder Judiciário.

Nesse contexto, as etapas de legalização de terrenos devem combinar a segurança fundiária, trazida pelo registro no cadastro de imóveis, com as particularidades que regem a gestão do solo no interior das favelas. Apoiando-se na análise de Etienne Le Roy et al. (1996, p.231 ss) sob o ponto de vista dos casos africanos, trata-se, assim, de consolidar uma visibilidade externa pelo registro do 
conjunto da área que compõe a favela, respeitando, no entanto, as especificidades inerentes à apropriação do solo no interior destas áreas. Como já ressaltamos antes, o emprego das ZEIS, as formas coletivas de usucapião ou de concessão de uso, o novo instrumento de demarcação urbanística, assim como o fortalecimento da figura da posse se revestem, de fato, dessa lógica.

A flexibilidade de aplicação da lei, sobretudo no que concerne às favelas, serve assim, como vimos, para manter a frágil paz social, endossando a estrutura socioespacial extremamente desigual das metrópoles brasileiras. Tal estrutura dificulta toda e qualquer medida, como a regularização fundiária, que vise integrar definitivamente esses espaços e seus habitantes ao resto da cidade. Novos instrumentos jurídicos previstos ultimamente pela legislação urbanística procuram reverter essa situação, consolidando, assim, uma regularização fundiária sustentável que permita tanto a legalização do solo nas favelas quanto a integração socioespacial dos seus habitantes. Aliando ao seu funcionamento lógicas institucionais e funcionais, o direito deve ser, finalmente, capaz de se adaptar às diversas questões sociais, mobilizando dispositivos de regulações próprias às particularidades locais, visando integrá-los plenamente à estrutura jurídica (Le Roy et al., 1996, p.269) em benefício da coletividade.

\section{Notas}

1 "It is a precondition for local investiment. Nobody invests if they feel insecure, and international experience shows that even the poor will invest what they can if they have reasonable security. Security is partly a matter of perception. Formal titles are not the only means of making people feel secure enough to invest in their homes and neighbourhoods" (UNHabitat, 2004, p.32).

2 Os direitos reais são direitos subjetivos particulares, que independem da vontade de terceiros. Eles concedem, assim, ao titular o controle direto sobre uma coisa. Esse controle é, além disso, eficaz contra terceiros. Trata-se, enfim, de direitos absolutos que valem erga omnes.

3 Ao evocar as disposições do usucapião especial urbano, o artigo $183(\$ 1)$ fez uma menção aparentemente deslocada sobre a concessão de uso, quando previu que o "título do domínio, e a concessão de uso serão conferidos ao homem, ou à mulher, ou aos dois, independentemente do estado civil". Determinados juristas levantaram o fato de que, apesar da ausência de dispositivos expressos sobre a concessão de uso, o emprego desse termo permitia pleiteá-la, invocando-se as mesmas disposições que a usucapião especial urbana, quando se tratasse de terrenos públicos.

4 A concessão de uso foi estabelecida pela Lei n.271 de 28 de fevereiro de 1967. Trata-se de um contrato por meio do qual o poder público atribui o uso exclusivo de um bem a uma pessoa física, para que ela o utilize de acordo com seu propósito específico, sob as condições estipuladas pela administração. O que é interessante na concessão de uso é o fato de que se trata de um direito real resolúvel, o que quer dizer que as autoridades poderão rescindir a concessão se o concessionário não respeitar as condições preestabelecidadas, ou então dar ao imóvel uma destinação diferente da que foi inicialmente proposta no contrato, o que dá às autoridades um grande controle sobre a utilização do 
bem. Essa concessão pode ser comercializada, transferida e deve, além disso, ser registrada no registro de imóveis (Vasconcelos, 1986, p.54).

5 Além da precariedade do texto legislativo que prevê a Cuem (uma medida provisória), um outro aspecto problemático é o limite temporal estabelecido pela MP (30 de janeiro de 2001). A ideia foi desestimular possíveis novas ocupações, mas acabou excluindo uma série de situações de fato, em que esse instrumento poderia ser plenamente aplicado.

6 Essa realidade sempre existiu nas favelas, mas tem tomado uma amplitude particularmente importante hoje em dia. Segundo o jornal O Globo de 31 outubro de 1999, oito famílias partilham entre si cerca de 500 imóveis nas quatro principais favelas do Rio (Rocinha, Rio das Pedras, Vidigal e Jacarezinho).

7 Ainda que o documento fornecido pela associação de moradores em si não proveja evidentemente a propriedade do bem, ele pode, além de legitimar a domínio do bem no interior da própria favela, provar o tempo total da posse, o que é fundamental, como vimos, para pleitear a Cuem e/ou a UEU. Diante das altas taxas cobradas pelas associações, muitos moradores não recorrem às associações, celebrando contratos "de boca".

8 Além dos custos sociais, não se pode esquecer de que os moradores das favelas possuem outros custos econômicos, como as diferentes taxas impostas pelos milicianos e traficantes.

9 Um dos diferentes aspectos falhos dessa MP foram as inúmeras competências, até mesmo de mediar conflitos entre proprietários e ocupantes, que foram concedidas aos oficiais de cartórios.

Referências bibliográficas

ALBUQUERQUE, A. R. V. Da função social da posse e sua consequência frente à situação proprietária. Rio de Janeiro: Lumen Juris, 2000. 229p.

COMBY, J. Reconnaître et sécuriser la propriété coutumière moderne. Etudes Foncières, n.128. p.38-44, 2007.

COMPANS, R. A regularização fundiária de favelas no Estado do Rio de Janeiro. Revista Rio de Janeiro, n.9, p.41-53, jan. abril 2003.

FERNANDES, E. Do Código Civil ao estatuto da cidade. Algumas notas sobre a trajetória do direito urbanístico no Brasil. Urbana, n.30. p.43-59, 2002.

GEERTZ, C. Savoir local, savoir global: les lieux du savoir. Paris: Presses Universitaires de France, 1999. p.207-90.

HOLSTON, J. Legallizando o ilegal: propriedade e usurpação no Brasil. Revista Brasileira de Ciencias Sociais, n.21, p.68-89, 1993.

LE ROY, E. Le jeu des lois. Une anthropologie "dynamique" du Droit. Paris: LGDJ, 1999. $415 \mathrm{p}$.

LE ROY, E. et al. La sécurisation foncière en Afrique. Pour une gestion viable des ressources renouvelables. Paris: Editions Karthala, 1996. 388p.

LIRA, R. Direito Urbanístico, Estatuto da Cidade e regularização fundiária. In: COUTINHO, R.; BONIZZATO, L. Direito da Cidade. Novas concepções sobre as relações jurídicas no espaço social urbano. Rio de Janeiro: Lumen Juris, 2007. p.1-15. 
OLIVEIRA, L. R. C. Droit légal et insulte morale. Montréal: Les Presses de l'Université Laval, 2005. 164p.

UN-HABITAT. Global campaign for secure tenure. A tool for advocating the provision of adequate shelter for the urban poor. Nairobi: UN-Habitat, 2004. 80p.

VASCONCELOS, J. A. M. de. Regularizaçao fundiaria e a urbanizaçao de areas faveladas em programas financiados pelo BNH. Rio de Janeiro: BNH, 1986. 89p.

RESUMO - As políticas de regularização fundiária das favelas consolidaram-se no Brasil como política urbana a partir do início dos anos 1980. Apesar dos avanços promovidos pela Constituição de 1988, o balanço registrado dos programas de legalização do solo é, todavia, negativo, revelando a complexidade e os limites da legislação urbanística brasileira. Esta contribuição visa analisar, brevemente, o contexto atual das políticas de regularização fundiária no país. Ao abordar os elementos do debate jurídico sobre a questão, este artigo procura compreender como a legalização do solo pode se tornar um instrumento crucial de integração socioespacial das camadas mais desfavorecidas das metrópoles brasileiras.

PALAVRAS-CHAVE: Regularização fundiária, Favelas, Segregação urbana, Direito à cidade. ABSTRACT - The policies of land regularization of the favelas were consolidated in Brazil like urban policy since at least the beginning of the 1980's. In spite of the consolidation of these policies after the Constitution of 1988, the result of these projects are rather negatives and reveals the complexity and the limits of the Brazilian urban law. This contribution especially aims at drawing up the current context of the land regularization in Brazil. By approaching the elements of the current legal debate on the land regularization, this article seeks to seize how the land legalization can be a public policy of social integration of the poorest urban population.

KEYWORDS: Land regularization, Slums, Urban segregation, Right to the city.

Rafael Soares Gonçalves é jurista e historiador, professor assistente do Departamento de Serviço Social da PUC-Rio e membro do Programa Setup.

@ - rafaelsgoncalves@yahoo.com.br

Recebido em 18.5.2009 e aceito em 2.6.2009. 